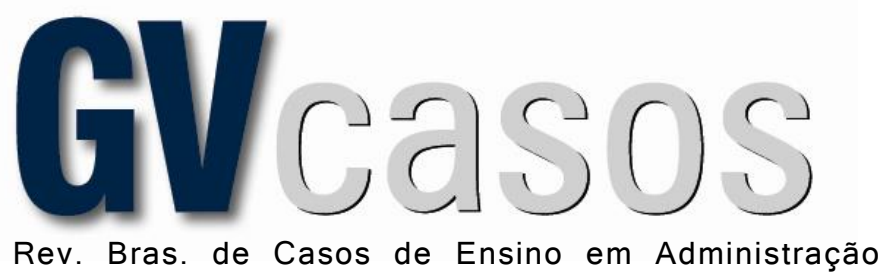

DOI: http://dx.doi.org/10.12660/gvcasosv11n1c2

\title{
HOMENS DE NEGÓCIOS NO SÉCULO XXI: TRÊS POSSIBILIDADES EM PERSPECTIVA
}

Businessmen in the 21st century: three possibilities in perspective

RODRIGO GUIMARÃES MOTTA - rodrigo-motta@uol.com.br

Pontifícia Universidade Católica de São Paulo - São Paulo, SP, Brasil

MARIA AMÉLIA JUNDURIAN CORÁ - mariaameliacora@ gmail.com

Pontifícia Universidade Católica de São Paulo - São Paulo, SP, Brasil

Submissão: 27/05/2020 | Aprovação: 19/01/2021

\begin{abstract}
Resumo
Manoel, Leandro e Joverley são homens de negócios brasileiros que construíram suas carreiras ao longo das últimas décadas do século passado e as primeiras deste. Com trajetórias de vida muito distintas, os três tiveram pontos de partida, familiar e social, diferentes, assim como a formação acadêmica e profissional. Mesmo assim, cada um à sua maneira, obteve destaque nos negócios, seja como empresário ou como executivo. A partir dessas três histórias de vida, os alunos são convidados pelo professor responsável por ministrar o caso de ensino a refletir de forma crítica sobre as disposições herdadas e adquiridas de cada um desses homens de negócios, sob a óptica da sociologia disposicionalista e dos conceitos de Pierre Bourdieu. Além disso, é introduzido o conceito de tipo ideal, tal qual elaborado por Max Weber, e o tipo ideal de homem de negócio contemporâneo, segundo o livro de Sá, O homem de negócios contemporâneo (2011), no qual versa sobre a proximidade entre os variados perfis. Os alunos são também orientados a fazer uma reflexão individual sobre os contextos social, acadêmico e econômico em que estão eles próprios inseridos e, nesse momento precoce de sua trajetória, de qual tipo ideal se aproximam como indivíduos.
\end{abstract}

Palavras-chave: Homem de negócios; Max Weber; Pierre Bourdieu; Sociologia Disposicionalista; Tipo Ideal.

\footnotetext{
Abstract

Manoel, Leandro, and Joverley are Brazilian businessmen who have built their careers over the past decades. Having had very distinct life trajctories, the three men enjoyed different family, social, educational, and professional backgrounds. Still, each one in his own way was professionally successful, either as a businessman or an entrepreneur. Based on these three life stories, the teacher responsible for the teaching case invites students to reflect critically on the inherited and acquired dispositions of each businessman, from the perspective of Dispositionalist Sociology and Pierre Bourdieu's concepts. In addition, the concept of Ideal Types is introduced as elaborated by Max Weber, and students analyze which Ideal Type of contemporary businessmen each profile is close to, according to Sá's book (2011). The teacher also asks students to reflect individually on which social, educational, and economic context they are inserted, and which Ideal Type they are close to, as individuals at an early stage of their trajectories.

Keywords: Businessmen; Max Weber; Pierre Bourdieu; Dispositionalist Sociology; Ideal Types.
} 
Este caso de ensino apresenta a trajetória de três homens de negócios, Manoel, Leandro e Joverley, provenientes de diferentes regiões brasileiras, que construíram suas carreiras profissionais em empresas ao longo das últimas décadas. Decorrente de trajetórias de vida e vivências de percurso diferenciadas, a formação acadêmica e profissional de cada um foi bastante díspar. Apesar dessas diferenças, todos perseveraram, seja em seus próprios negócios ou em grandes empresas e atingiram posições de destaque no ambiente corporativo. Seu objetivo é estimular o entendimento de quem são os homens de negócios, em especial, os executivos brasileiros e, a partir da definição de tipo ideal de Weber refletir sobre os tipos ideais de homens de negócios contemporâneos. Outra contribuição deste caso de ensino é introduzir os princípios da sociologia disposicionalista, em especial os conceitos elaborados por um de seus principais autores, Pierre Bourdieu. A última contribuição do caso de ensino é incentivar o aluno a refletir sobre sua própria trajetória e descobrir qual tipo de homem de negócios mais se aproxima da sua própria história. Formado para os negócios? Ascendente social por meio dos negócios? Herdeiro da tradição do comércio?

\section{Manoel}

Manoel Antônio Ribeiro Machado nasceu na cidade de São Paulo, no final da década de 1950. O mais novo de três irmãos, sua família era de uma sólida classe média, descendente de portugueses. Seu pai era delegado de polícia e sua mãe, até o falecimento do marido aos 40 anos, administrava o lar. Depois disso, passou a trabalhar como corretora de imóveis. O pai e a mãe incutiram em Manoel uma disciplina muito rígida e o impulsionaram rumo aos estudos. Assim cursou colégios tradicionais, aprendeu inglês.

Com todo o apoio do pai, que sonhava ter um filho militar, Manoel cursou o segundo grau na Escola Preparatória de Cadetes do Exército (Especx) por acreditar, naquele momento, que a carreira militar seria uma profissão de maior potencial e prestígio. Ao concluir o curso, porém, optou por não dar continuidade à carreira militar, muito influenciado pelo falecimento de seu pai.

Ouso dizer que a morte dele permitiu que não tivesse que enfrentá-lo com a minha decisão em não ser um militar e seguir uma carreira nos negócios. Meu pai tinha essa fixação com a carreira militar, o sonho dele era ter sido militar, que para a época em que viveu era o máximo. Mas minha mãe sempre apoiou minhas escolhas e nunca me dirigiu para um lado ou para outro. Foi assim que, naquele momento, decidi cursar Administração de Empresas.

Realizou, então, um curso de computação e começou a trabalhar com programação, uma atividade em ascensão na época, ainda sem ter entrado na faculdade. Prestou vestibular para a Escola de Administração de Empresas de São Paulo da Fundação Getúlio Vargas (EAESP - FGV), considerada uma das melhores escolas do Brasil. Decidiu realizar o curso noturno a fim de trabalhar durante o dia e ganhar dinheiro, sua primeira grande ambição, motivado pelas histórias de empresários e executivos de sucesso a que assistia em programas, aprofundava-se em leituras ou em conversas com amigos.

Ainda quando cursava os primeiros anos do curso de Administração foi trabalhar na Arthur Andersen, uma empresa de auditoria e consultoria. Após se formar, foi admitido na área de marketing da Johnson \& Johnson, uma empresa na qual todos os jovens executivos nos anos 1980 almejavam trabalhar. Nessa empresa, chegou ao cargo de gerente de grupo de produtos, tendo inclusive morado um ano e meio nos Estados Unidos, experiência que a organização oferecia aos seus melhores talentos.

Com uma carreira em ascensão, foi procurado pela Procter \& Gamble, que no início da década de 1990 havia acabado de entrar no Brasil, adquirindo a tradicional empresa Phebo, para 
assumir uma gerência no departamento de marketing. Atraído pelo desafio, Manoel aceitou e mudou de empresa. Nessa empresa, trabalhou não apenas na área de marketing, como também na área de vendas, sempre com resultados de destaque. Formou muitos profissionais, que não só contribuíram para o seu sucesso, mas, também, mais tarde se uniram a ele em outros projetos profissionais.

Manoel, mesmo sendo bastante jovem, diante da sua trajetória profissional, foi procurado pela fabricante italiana de chocolates Ferrero para abrir a operação da empresa no Brasil. Após conhecer a empresa, os produtos e a família proprietária do negócio, decidiu aceitar o desafio, em 1994. Nos anos seguintes, a Ferrero, sob a liderança de Manoel, formou um time com muitos dos profissionais que haviam trabalhado com ele em outras empresas, e lançou produtos que foram muito bem-sucedidos no mercado, como Kinder Ovo, Ferrero Rocher, Tic Tac e Nutella.

Esses resultados fizeram com que outras empresas passassem a prospectar o executivo, oportunizando, dessa forma, que chegasse a presidir outras empresas de renome, como a Danone e a Kimberly Clark.

No início dos anos 2000, com uma carreira consolidada, decidiu reciclar seus conhecimentos e ampliar horizontes. Foi assim que se mudou para Londres, onde fez mestrado em Administração na conceituada London Business School.

Sempre fui muito dedicado ao trabalho e compromissos com a minha formação, mas também aproveitei a vida. A oportunidade de estudar fora do país permitiu que eu pudesse conciliar esses múltiplos interesses: estudei o estado da arte da administração da época, morei fora com minha família por algum tempo e viajamos muito, sempre que possível nesse período, já que estávamos vivendo na Europa.

Após retornar ao Brasil, passou a dar aulas em cursos de pós-graduação em Administração de Empresas e realizou consultorias para importantes empresas, com destaque para a PomPom (que produzia, entre outros bens de consumo não duráveis, fraldas descartáveis). Dedicado a aulas e consultorias, surgiu uma oportunidade profissional diferente.

Mudou de ramo e se tornou empresário quando, a convite de um amigo, tornou-se seu sócio e passou a administrar a Unotech, empresa que comercializa lubrificantes para a indústria pesada. A família também progrediu nesse período: seus filhos, do primeiro casamento, se formaram em direito e engenharia e iniciaram suas carreiras profissionais, e Nora, sua atual esposa, ocupou cargos de liderança em empresas multinacionais de bens de consumo, como a Pepsico.

Em 2017, Manoel foi convidado a presidir a Enova Foods, empresa que pertence a dois fundos de investimento e atua nas categorias de refrescos em pó, snacks e barras de nuts. Durante os anos seguintes, novamente se cercou de pessoas de sua confiança, com experiência comprovada, e liderou a empresa rumo à profissionalização e consolidação no mercado.

Tendo concluído essa segunda experiência como executivo no primeiro semestre de 2020, seu próximo passo de carreira é atuar em conselhos de administração. Sua filha mais nova já está na universidade, cursando Administração de Empresas, e Nora presta consultoria. Nesse novo momento de vida, Manoel planeja seu próximo passo na carreira, ao mesmo tempo que se dedica com afinco aos seus passatempos preferidos: viajar, cozinhar e preparar cervejas artesanais. Relata Manoel:

Tenho conhecimentos de estratégia e operações em diversos segmentos de negócios, nos quais atuei como empresário e executivo, e experiência profissional e acadêmica suficiente para contribuir com empresas que buscam posições de destaque no Brasil. Já vi e fiz muitas histórias de sucesso no mundo empresarial, errei também. Em conselhos de administração possuo muita energia para oferecer. Estou muito entusiasmado com o que vem pela frente. 


\section{Leandro}

Leandro Pereira de Lacerda nasceu no interior do estado do Paraná, na pequena cidade de Tijucas do Sul, mas, ainda criança, a família se mudou para São José dos Pinhais. De origem muito humilde, seu pai era lavrador e sua mãe administrava o lar. Leandro é o filho mais novo da família, e tem três irmãos mais velhos. Algumas vezes Leandro ajudava seu pai, que sempre dizia, com muito orgulho, que seu filho era muito bom com as contas. Seus pais incutiram nos filhos a importância de ser alguém que tivesse valores bem estabelecidos, os quais eles acreditavam ser imprescindíveis para que seus filhos tivessem uma vida ainda melhor que a deles.

Acho que meus pais sempre esperaram que eu seguisse seus valores. Ser alguém honesto, leal, que valoriza e apoia a família no que for necessário. E também alguém que fosse trabalhador, comprometido com seu emprego. Minha mãe sempre usa esse termo quando se refere a minha trajetória de vida, e por esse depoimento, posso ver o quanto ela está orgulhosa do que construí com o apoio deles.

Quando criança, ainda com dez anos, seu pai faleceu de câncer e a mãe teve que trabalhar como diarista para sustentar a casa e oferecer condições mínimas e dignas para que os seus quatro filhos estudassem. Apesar de ambos os pais não terem concluído o primeiro grau, o sonho deles era que os filhos estudassem, se formassem no colégio e quem sabe na faculdade. Mesmo com os filhos estudando em colégios públicos, a mãe das crianças tinha muita dificuldade para pagar todas as contas, afinal eram cinco pessoas dependendo do seu salário. Mesmo assim, continuou incentivando os filhos a estudar, algo que via como fundamental para que eles progredissem econômica e socialmente.

Foi por essa necessidade familiar, para ajudar a reduzir as despesas familiares, que Leandro entrou no programa de menor aprendiz aos quinze anos e começou sua carreira profissional muito jovem, na tradicional empresa paranaense Nutrimental, fabricante de barras, refrescos em pó e farinhas modificadas, localizada em São José dos Pinhais. Nunca teve dúvidas de que deveria estudar, para apoiar a família e ter um futuro melhor para si e para aqueles próximos a ele.

Na Nutrimental, Leandro construiu sua carreira, passando por diversas áreas, como finanças, Administração de vendas e trade marketing. Simultaneamente, concluiu o segundo grau e, incentivado pelos seus colegas de trabalho, que percebiam a sua capacidade matemática e seu raciocínio lógico, estudou administração de empresas. Não foi uma decisão simples, pois apesar do seu precoce destaque profissional na administração, gostava de ler, de explorar novos campos de conhecimento. Chegou a pensar em cursar jornalismo, mas mentores e amigos acabaram por convencê-lo a seguir a carreira de administrador.

Por outro lado, permaneceu sua curiosidade por outros temas, e complementou sua formação acadêmica com estudos livres sobre filosofia, sua paixão, o que ampliou sua capacidade de analisar desafios complexos e buscar soluções inovadoras e lógicas, fortalecendo suas habilidades como gestor.

Sua experiência profissional combinada com a experiência acadêmica permitiu a Leandro desenvolver uma capacidade analítica, que não só o capacitava a compreender a dinâmica da empresa como um todo, como também a encontrar oportunidades de negócios e soluções para muitos problemas.

Sempre muito talentoso, contou também com gestores que enxergaram seu potencial e apoiaram o seu desenvolvimento, oferecendo constantemente novos desafios e propondo cursos e estudos complementares. Isso chamou a atenção da diretoria da Nutrimental, e ele passou a realizar a gestão do desempenho dos indicadores da empresa, reportando-se ao próprio presidente, que analisava os indicadores regularmente junto com os demais diretores. Isso com apenas 25 anos. 
Profissionalmente, eu me deparei em minha primeira experiência profissional na Nutrimental com algumas figuras que me inspiraram na minha formação. A primeira pessoa que me inspirou e me deu oportunidades foi um gestor que tive, que acreditou em mim, criou oportunidades e atuou no meu desenvolvimento. Depois me deparei com outro gestor que me colocou desafios ainda maiores, acreditou em mim. E meu terceiro incentivador foi aquele que mais tarde me convidou a desenvolver também projetos de consultoria. Hoje me considero um profissional multidisciplinar e cada uma dessas pessoas desempenhou o seu papel na minha formação.

Pessoalmente, Leandro se casou com Paloma, atualmente estudante de pedagogia, e, junto com ela, realizava trabalhos sociais na Cia da FelizCidade, na qual coordenava um grupo de palhaços voluntários que visitavam os pacientes internados no Hospital e Maternidade Municipal de São José dos Pinhais, para oferecer uma experiência leve e divertida àqueles que estavam passando por um tratamento de saúde penoso.

Com muita experiência, apesar da idade, e com sua vida familiar estabilizada, Leandro sentiu vontade de retomar os estudos, fazendo seu curso de mestrado. A oportunidade surgiu quando um ex-colega e amigo, Rodrigo, que trabalhou na Nutrimental, o convidou para desenvolver projetos de consultoria na RGMotta Consultoria de Impacto.

Leandro se entusiasmou com a possibilidade, pediu demissão da Nutrimental, no final de 2016, e começou a realizar consultoria nas áreas em que possuía experiência, para empresas de diversos segmentos de negócios, tais como White Wave, Diletto, Flora, Enova Foods, Vita Ortopedia e Reabilitação, Roots to Go, Lowko.

Ao mesmo tempo que desenvolvia esses projetos, sempre com resultados reconhecidos pelos clientes, foi admitido no mestrado em Administração da Pontifícia Universidade Católica do Paraná, PUC-PR. O sucesso obtido com os trabalhos de consultoria despertou a atenção das empresas com as quais Leandro trabalhava e, quando concluiu o mestrado, em 2019, foi convidado a assumir a gerência financeira de uma das empresas para as quais prestava consultoria, o Vita Ortopedia e Reabilitação, uma empresa sediada em São Paulo, que oferece serviços ortopédicos e de fisioterapia.

Leandro aceitou o desafio, que o entusiasmou não somente pelo cargo e pelas condições de trabalho, mas também porque o Vita trabalha na área de saúde, algo bem diferente da sua experiência pregressa como executivo. O único inconveniente era a empresa sediada em São Paulo, e Leandro ainda morava com sua esposa em São José dos Pinhais. Após uma conversa, o casal concordou que a mudança seria uma excelente oportunidade de crescimento tanto pessoal quanto profissional.

Atualmente, Leandro trabalha em São Paulo, e segue entregando resultados sólidos para os acionistas, conseguindo fazer boa gestão profissional e a expansão das suas unidades de negócios. Ele se sente muito feliz com isso, e aproveita também as horas vagas e os finais de semana para conhecer mais a cidade, junto com sua esposa. Tem também preparado artigos acadêmicos, a partir da pesquisa de sua dissertação de mestrado.

Me sinto muito motivado com minha situação atual, parece que tudo o que aprendi ao longo de quinze anos de atuação profissional está sendo útil. Espero que o Vita continue crescendo cada vez mais e que eu possa crescer junto com o negócio. Assim poderei ajudar minha mãe, que ainda mora no Paraná, a adquirir um imóvel em São Paulo, quem sabe em 2021 ou 2022 ingressar no doutorado...e em algum momento ter filhos.

\section{Joverley}

Joverley de Paula ainda muito jovem se mudou com sua família para Monte Azul, no norte 
do estado de Minas Gerais, em meados da década de 1970. Foi o filho caçula, tendo quatro irmãos mais velhos. Sua família era muito tradicional na região, tanto por parte de pai, quanto por parte de mãe. Enquanto as mulheres se dedicavam ao magistério ou administravam o lar, os homens tinham seus próprios estabelecimentos comerciais ou trabalhavam como funcionários públicos. Uma tragédia ocorreu quando Joverley tinha apenas um mês de vida: seu pai, com 33 anos, foi assassinado por um adversário político.

Sua mãe, viúva e com cinco filhos para criar, passou a ministrar aulas, além de receber apoio financeiro de seu pai que gozava de uma boa situação econômica, obtida através do trabalho no supermercado da família, na cidade de Ceilândia, no Distrito Federal.

Mais tarde, Joverley se mudou com a família para Montes Claros, também no norte de Minas. À medida que crescia, cursava o colégio em Montes Claros e passava alguns dias das suas férias escolares em Ceilândia, com o avô materno, aprendendo a trabalhar com seus parentes, tanto no supermercado como em outros negócios que a família possuía. Após concluir o segundo grau, morou três anos com sua família no Distrito Federal.

Eu já conhecia como funcionava o supermercado, mas quando passei mais tempo lá, após ter concluído o colégio, entendi como funcionavam todas as áreas, passei a trabalhar com os meus tios e primos e logo eu estava atuando em todas os departamentos da empresa. Pude ajudar com compras, administração, gestão de pessoas, promoções de vendas, eu fazia de tudo um pouco e, assim, não só ajudei o negócio a crescer, como me formei um comerciante.

Joverley não demonstrou interesse cursar uma faculdade, ainda que uma de suas irmãs insistisse e o houvesse apoiado a realizar um cursinho preparatório, na cidade de Curitiba, onde ela morava na época. Joverley se mudou para lá e continuou os estudos, mas sem o mesmo entusiasmo que demonstrou para ajudar no supermercado. Ele queria trabalhar, ter o seu próprio negócio, assim como seus familiares no Distrito Federal. Comprar e vender era algo que ele acreditava ter nascido para fazer, um dom. Tinha uma influência muito forte dos exemplos familiares, e, além do mais, era algo que ele sabia fazer e que acreditava que poderia aproximá-lo mais rapidamente da realização dos seus sonhos.

Eu já estava matriculado para prestar o vestibular na Universidade Federal do Paraná, era um excelente aluno no cursinho e estava confiante para ser aprovado na UFPR, mas se eu fosse estudar quatro anos na faculdade, para depois trabalhar em uma empresa, eu iria demorar muito para conquistar o que eu queria. Naquele momento tinha muitos sonhos, queria ter uma moto, um carro, viajar pelo Brasil, e a trilha convencional de estudar e depois trabalhar me pareceu muito longa e pouco atraente, afinal eu já estava com mais de 20 anos. E queria trabalhar para poder conquistar aquilo que desejava.

Enquanto estudava no cursinho preparatório, trabalhou em uma imobiliária de Curitiba e economizou dinheiro ao longo de um semestre. Voltou para Montes Claros e, com o dinheiro economizado, iniciou a compra de computadores usados, que recebiam manutenção, para em seguida revendê-los a empresas e pessoas. O bom resultado das primeiras vendas, a princípio feitas na casa de sua mãe e depois em uma sala alugada (os produtos eram divulgados em jornais especializados), permitiu que ele abrisse uma loja, a fim de comercializar os computadores. Dessa forma, seu negócio prosperou e ele logo obteve independência financeira de sua família, em especial da mãe, que sempre esteve ao seu lado e o apoiou quando necessário. 
Nesse período, Montes Claros apresentava um bom desenvolvimento econômico, o que contribuiu para que os negócios continuassem crescendo. Nessa época, Joverley havia construído uma casa para morar, mas tão logo a concluiu, recebeu uma proposta de uma pessoa interessada em comprá-la, e o imóvel foi vendido. Atento às movimentações econômicas e sociais, e sempre em busca de oportunidades para iniciar novos negócios, viu que a cidade e seus moradores estavam receptivos a empreendimentos imobiliários e decidiu expandir sua atuação, abrindo uma construtora, com a intenção de oferecer alternativas para comércio e residência àqueles que, como ele, estivessem se beneficiando do desenvolvimento da cidade.

O sucesso desse empreendimento acabou estimulando-o a encerrar seu negócio na área de computadores, que também enfrentava à época a concorrência de varejistas nacionais que haviam se estabelecido na cidade, vendendo computadores com preços competitivos e em múltiplas parcelas do cartão de crédito, e se dedicar integralmente à construtora.

Como adquiria muitos materiais de construção para as obras em que estava envolvido, observou que a demanda desses produtos em sua cidade era maior do que a oferta e decidiu ampliar sua atuação abrindo, então, uma loja de materiais de construção, o Depósito Amigão, que vendia os produtos não apenas para sua própria construtora, mas também para o público em geral, que estivesse construindo ou reformando seus imóveis.

Atualmente, vive com a esposa Bárbara, ela própria uma bem-sucedida comerciante, que possui uma loja de roupas femininas no centro da cidade, e com sua filha Ana Laura. Sempre atento aos seus negócios e às novas oportunidades, nas poucas horas vagas disponíveis que se apresentam, aproveita para visitar os parentes e para viajar de carro pela região e para a praia, em estados próximos, como a Bahia, junto com sua família. Joverley e Bárbara são muito determinados em seus negócios e esperam, com sorte, desenvolvê-los, tendo como foco se aposentar até os 60 anos.

Dá muito trabalho cuidar de todos os negócios que administro, mas me esforço muito para concluir os projetos da construtora com a maior qualidade possível e com custos adequados, para oferecer uma excelente alternativa imobiliária a um preço justo. Minha clientela reconhece isso, e a maior parte dos novos clientes vem do boca a boca. Espero poder repetir o sucesso com o Depósito Amigão. Sei que não é fácil, tenho que acordar cedo e trabalhar o dia inteiro, mas isso é o que gosto, sei fazer e que poderá permitir que eu realize os meus sonhos. 